\title{
Measurement of respiratory muscle strength
}

Why must the chest physician become familiar with assessment of the respiratory muscles? Firstly, because dyspnoea in patients in whom no pulmonary cause can be detected may be due to respiratory muscle weakness. ${ }^{12}$ Even moderately severe muscle weakness may be difficult to detect clinically ${ }^{3}$ and, indeed, it is possible to have total paralysis of the diaphragm without life threatening consequences. ${ }^{4}$ Secondly, because patients with clearly documented generalised neuromuscular disease usually also have respiratory muscle weakness ${ }^{2}$ and, for selected cases, treatment in the form of non-invasive ventilation is indicated. ${ }^{5}$ Finally, there has recently been increased awareness that respiratory muscle weakness can be a compounding factor in other disease processes such as malnutrition ${ }^{6}$ and steroid therapy. ${ }^{7}$ For all of these reasons it is important for respiratory physicians to initiate and to be able to interpret simple tests of respiratory muscle function. For most patients the suspicion of clinically important respiratory muscle weakness may be confirmed or excluded by simple tests that can be performed in the general hospital setting without the purchase of expensive equipment, but in some patients complex tests in a specialised laboratory are necessary (fig 1). In this editorial the current techniques to assess respiratory muscle strength are reviewed with

Is unexplained breathlessness due to respiratory muscle weakness?
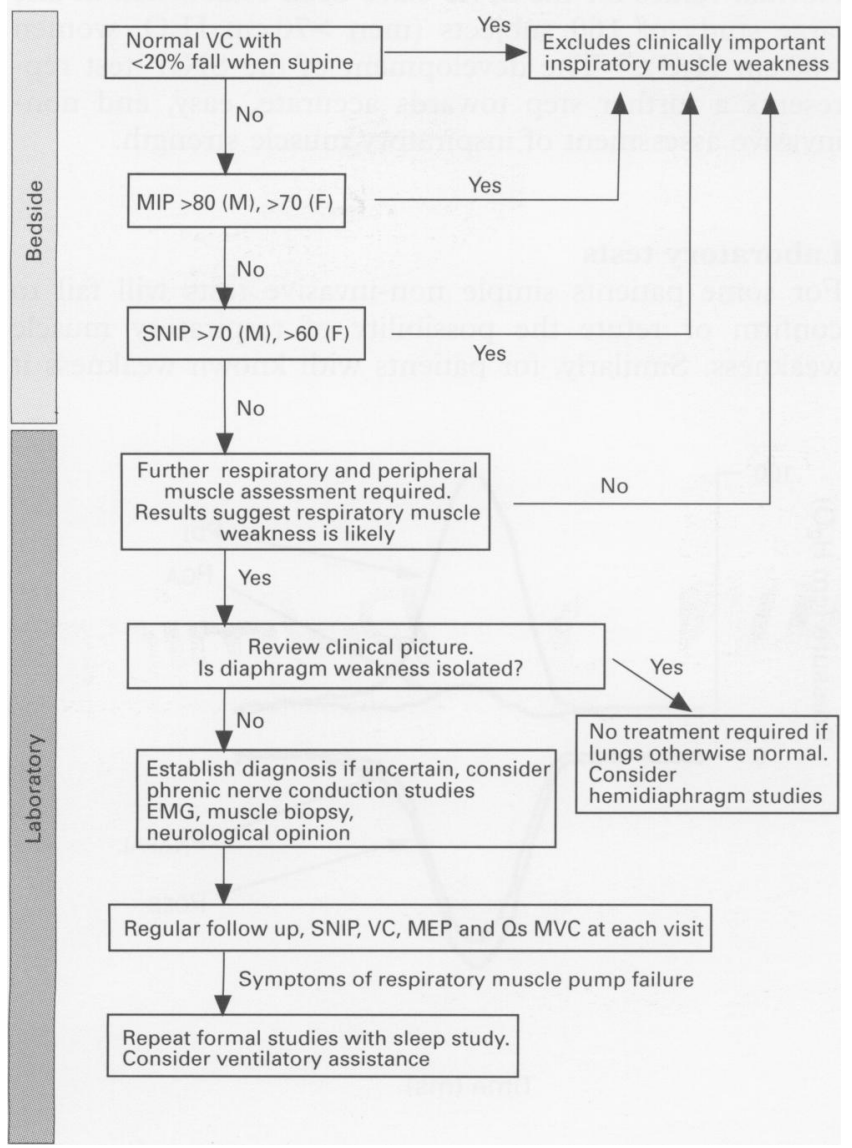

Figure 1 Algorithm for the approach to assessment of the respiratory muscles. An incremental approach is used for most patients. For the remainder, comprehensive specialist tests are indicated. $V C=v i t a l$ capacity; $M I P=$ maximum inspiratory pressure; $M E P=$ maximum expiratory pressure; $S N I P=$ sniff nasal inspiratory pressure; $Q s=$ quadriceps; $M V C=$ maximum voluntary contraction force. reference to these two different environments. Respiratory muscle fatigue will not be addressed, but has been reviewed recently. ${ }^{89}$

\section{Bedside and clinic tests \\ HISTORY AND EXAMINATION}

History and examination may confirm features of the many conditions, both neurogenic and myopathic, that can cause respiratory muscle weakness. In generalised neuromuscular disorders it is unusual for the respiratory muscles to be spared. Wasting and fasciculation of the limb and accessory muscles can be striking as, for example, in motor neurone disease. Severe generalised respiratory muscle weakness causes breathlessness and tachypnoea. Breathlessness when sitting or standing in water, or when supine, is a specific feature of severe diaphragm weakness. When generalised weakness becomes sufficiently severe nocturnal hypoventilation disrupts sleep, causing daytime somnolence and impaired intellectual function. ${ }^{10}$ Eventually ventilatory failure and cor pulmonale develop. Weakness of bulbar and expiratory muscles impair cough and so predispose to aspiration and pneumonia.

On examination the characteristic finding of profound bilateral diaphragm weakness or paralysis is paradoxical inward inspiratory abdominal motion; this is more obvious with the patient supine. ${ }^{4}$ As a consequence of poor diaphragm contractility accessory muscle activity greatly increases when ventilation is increased and, when upright, the abdominal muscles may be visibly recruited during expiration, serving to elevate the diaphragm and allowing subsequent gravitationally assisted descent during inspiration. ${ }^{11}$ These clinical features are seldom present until diaphragm strength is reduced to about a quarter of normal; thus, substantial diaphragm weakness can be overlooked on clinical examination. ${ }^{2}$

\section{IMAGING}

In hemidiaphragm paralysis an elevated hemidiaphragm may be visible on chest radiography. With substantial bilateral diaphragm weakness the chest radiograph may show elevated hemidiaphragms, but can appear relatively normal. ${ }^{4}$ Similarly, a cephalad movement of the diaphragm is commonly observed on fluoroscopy during inspiratory manoeuvres but this test has the twin disadvantages of both a significant false positive rate ${ }^{12}$ and that little information about the degree of diaphragm weakness is provided. The best manoeuvre is a short sharp submaximal sniff. In bilateral paralysis pre-inspiratory elevation of the diaphragm by the abdominal muscles may restore the normal caudal motion giving rise to false negatives. ${ }^{11}$ Hemidiaphragm movement may also be semiquantitatively assessed using ultrasound which has the advantage of avoiding irradiation. ${ }^{13}$

\section{LUNG FUNCTION}

On lung function testing the characteristic abnormality of inspiratory muscle weakness is a low vital capacity (VC) with a reduced total lung capacity (TLC) and preserved residual volume (RV). Carbon monoxide transfer is reduced, but is normal or raised when adjusted for volume, 
and this serves to distinguish respiratory muscle weakness from alveolar disorders such as pulmonary fibrosis. ${ }^{2}$

Measurement of VC is of great value. An entirely normal VC makes significant respiratory muscle weakness unlikely. In subjects with diaphragm weakness the VC falls when the patient is supine, though this fall must exceed $25 \%$ to be unequivocally abnormal. ${ }^{14}$ Thus, a normal supine VC excludes clinically relevant inspiratory muscle weakness. In longstanding weakness the VC may fall further because of reduced chest wall and lung compliance, possibly associated with microatelectasis, ${ }^{15}$ though this in itself does not detract from the diagnostic value of the test. The VC is of value for frequent monitoring of patients at risk of rapidly progressive muscle weakness or paralysis, the best clinical example being Guillain-Barré syndrome. ${ }^{16}$ However, measurement of VC is volitional and relies on patient motivation and ability. Use of an anaesthetic style facemask may help if disease precludes the use of a mouthpiece. Apart from depending on effort and cooperation by the patient, a major limitation of $\mathrm{VC}$ is that it is reduced by factors other than weakness: a low VC can therefore be non-specific and non-diagnostic.

Overnight pulse oximetry, performed as an inpatient or in the patient's home, can, if normal, provide evidence that any weakness is not sufficiently severe to cause overt ventilatory failure. Conversely, the demonstration of nocturnal hypoventilation signifies that respiratory muscle weakness is sufficiently severe to lead to ventilatory failure. Sleep studies may therefore be of value in the assessment of the load/capacity balance in such patients; substantial nocturnal desaturation does not occur until global respiratory muscle strength is reduced to below one third of normal in patients with neuromuscular disease alone, but occurs earlier if there is coexisting respiratory disease increasing ventilatory load (see below).

\section{MOUTH PRESSURES}

The most widely applied tests of global inspiratory and expiratory muscle strength are the static inspiratory and expiratory pressures measured at the mouth (MIP and MEP). These tests have the advantage that they are noninvasive and normal values have been established in quite large series. ${ }^{17-21}$ Conventionally, MIP is measured from RV although this has the theoretical disadvantage that recoil of the chest wall contributes to the value obtained. In practice patients find the manoeuvre easier from $\mathrm{RV}$ than functional residual capacity (FRC) and, for the purpose of screening out patients who do not have inspiratory muscle weakness, the difference is not important. Portable inexpensive mouth pressure meters allow immediate measurement of the MIP and MEP at the bedside or in the clinic. ${ }^{22}$ As with the VC a high MIP (say $>80 \mathrm{~cm} \mathrm{H}_{2} \mathrm{O}$ ) is of great value in excluding clinically important inspiratory muscle weakness.

Whilst a high MIP, by excluding inspiratory muscle weakness, is a valuable piece of clinical information, a lower value is frequently difficult to interpret. One problem with static pressures is that they are volitional; thus, for the result to be a true measure of strength the subject must make a maximal contraction. If three equal "maximum" efforts are obtained then it is conventionally assumed that the subject is making a maximal effort, but it has recently been shown that reproducibility does not ensure maximality. ${ }^{23}$ To assess the degree of voluntary effort it is possible to stimulate electrically the nerves supplying the diaphragm during the contraction; if no additional transdiaphragmatic pressure (PDI) is observed then the contraction is considered to be maximal (the twitch occlusion technique). Using this technique maximal activation of the diaphragm during the MIP manoeuvre has been demonstrated in some, but not all, normal subjects ${ }^{24}$ and patients. ${ }^{2627}$ Values tend to be higher with a tube mouthpiece, but patients find this difficult to use so a flanged type is the norm. ${ }^{28}$ Patients with neuromuscular disease involving the orofacial muscles may have difficulty in forming an airtight seal around either type of mouthpiece, and this will lead to an underestimation of static pressures. With the development of new tests of inspiratory muscle strength (see below) the MIP may not be the most suitable measurement when a reproducible quantitative assessment is required as, for example, in studies of respiratory muscle training. The MEP is subject to the same concerns as the MIP but, unlike the MIP, there are no alternative tests currently available outside specialised laboratories.

\section{NASAL PRESSURES}

The sniff is a natural manoeuvre which many patients find easier to perform than static efforts. ${ }^{29}$ In normal subjects the pressure measured in the oesophagus during a sniff is closely related to that in the mouth, nasopharynx, and nose (fig 2). ${ }^{30-32}$ Thus, in both normal subjects and patients with inspiratory muscle weakness the sniff nasal inspiratory pressure (SNIP) provides a reasonable estimate of inspiratory muscle strength. ${ }^{32}$ In patients with chronic obstructive pulmonary disease (COPD) the SNIP, unlike the MIP, underestimates strength ${ }^{33}$; this is expected because the sniff is a short manoeuvre and the transmission of the pressure response from the oesophagus to mouth and nose is dampened in COPD. ${ }^{34}$ The SNIP can be particularly helpful when deciding whether to pursue the finding of a low MIP and can also be performed at the bedside. ${ }^{35}$ Normal values for the SNIP have been established in one large study of 160 subjects (men $>70 \mathrm{~cm} \mathrm{H}_{2} \mathrm{O}$, women $>60 \mathrm{~cm} \mathrm{H} \mathrm{H}_{2} \mathrm{O}$ ). ${ }^{36}$ The development of the SNIP test represents a further step towards accurate, easy, and noninvasive assessment of inspiratory muscle strength.

\section{Laboratory tests}

For some patients simple non-invasive tests will fail to confirm or refute the possibility of respiratory muscle weakness. Similarly, for patients with known weakness it

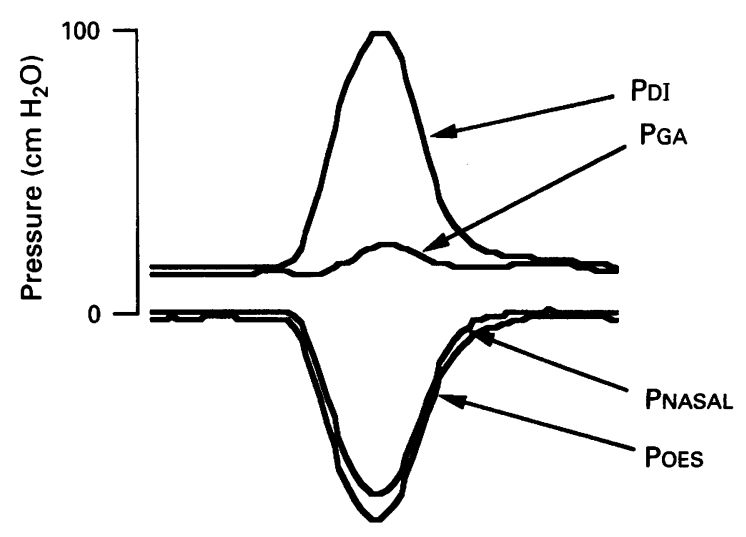

Time (ms)

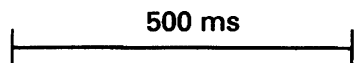

Figure 2 Pressures produced by a sniff in a normal subject. PNASAL is observed to follow POES closely. PDI=transdiaphragmatic pressure; $P G A=$ gastric pressure; POES =oesophageal pressure. 
is sometimes important to make a precise estimation of the weakness in order to make decisions about management. For these patients formal assessment of respiratory muscle strength is required, and this assessment should include non-volitional tests. Placement of oesophageal and gastric balloons using topical anaesthesia allows measurement of oesophageal, gastric, and transdiaphragmatic pressure, and also dynamic compliance. We have made such measurements in many hundreds of patients in our laboratories over the last 20 years, achieving successful placement of balloons in over $95 \%$ of patients.

\section{SNIFF Pdi AND PoEs}

Amost all patients are able to make maximum sniff efforts. The sniff is performed from FRC with no noseclip. When thus performed the volume increase is small, about $500 \mathrm{ml},{ }^{37}$ and diaphragm contraction is therefore relatively isometric. In normal subjects sniff transdiaphragmatic pressure (sniff PDI) has a narrower normal range and a better between day coefficient of variation than the MIP manoeuvre. ${ }^{29}$ In patients about one sixth have a low MIP but a normal sniff oesophageal pressure (sniff POES normal values, men $>80 \mathrm{~cm} \mathrm{H} \mathrm{H}_{2} \mathrm{O}$, women $>70 \mathrm{~cm} \mathrm{H} \mathrm{H}_{2} \mathrm{O}$ ). Since the diaphragm is normally the most important single muscle of inspiration it is not surprising that sniff PoEs, a measure of global inspiratory muscle strength, is closely related to sniff PDI, a specific measure of diaphragm strength. Thus, diagnostically useful information about inspiratory muscle strength and, by inference, diaphragm strength may be obtained with a single oesophageal catheter/transducer system as routinely used for the measurement of lung compliance. ${ }^{38}$ In clinical practice sniff PoES and sniff PDI are the most accurate and reproducible volitional tests currently available to assess global inspiratory and diaphragmatic strength.

\section{NON-VOLITIONAL TESTS: PHRENIC NERVE STIMULATION Electrical stimulation}

Although sniff pressures are considerably more accurate and reproducible than MIP, the sniff manoeuvre does require the understanding and cooperation of the patient. Electrical phrenic nerve stimulation (ES) in the neck and the measurement of twitch PDI has the advantage of eliminating variation due to patient motivation and also allows measurement of the EMG signal and nerve conduction time (normal (SD) range $7 \cdot 7(0 \cdot 8) \mathrm{ms}) .^{39}{ }^{40} \mathrm{In}$ isolated fresh mammalian skeletal muscle preparations there is a constant relationship between the force generated by a single twitch and the force generated by a tetanic fusion of contractions, the twitch:tetanus ratio. ${ }^{41}$ With electrical phrenic nerve stimulation, when supramaximal, the relationship between twitch PDI and maximum sniff PDI is similar to the twitch: tetanus ratio observed in isolated mammalian muscle. ${ }^{42}$ However, precise electrode placement is essential if a truly supramaximal stimulation is to be achieved. To accomplish this repeated stimulations are frequently required and, since electrical stimulation is painful, this limits the extent to which the technique can be used in clinical studies. Patients may find it difficult to relax during electrical phrenic nerve stimulation, thereby causing an increase in twitch tension - the phenomenon of twitch potentiation. ${ }^{4344}$ Nevertheless, bilateral electrical phrenic nerve stimulation has been used to measure twitch transdiaphragmatic pressure in normal subjects ${ }^{4245}$ and patients. ${ }^{4647}$ Perhaps because of the reasons discussed above, the reported normal range is wide $\left(8 \cdot 8-33 \mathrm{~cm} \mathrm{H}_{2} \mathrm{O}\right)$ making it diagnostically useful only when there is severe weakness or, when the result is unequivocally normal (thus excluding weakness), in patients unable or unwilling to perform volitional tests. ${ }^{48}$ Hemidiaphragm function may be usefully assessed by unilateral electrical stimulation of the phrenic nerves. ${ }^{49}$

\section{Magnetic stimulation}

Many of the problems associated with electrical stimulation have been largely overcome by the introduction of magnetic stimulation of the phrenic nerves. By discharging a magnetic coil it is possible to create a pulsed magnetic field which causes current to flow in nervous tissue within the field which in turn causes muscle to contract. ${ }^{5051}$ Supramaximal bilateral phrenic nerve stimulation may be achieved using a circular coil placed over the cervical phrenic nerve roots. ${ }^{553}$ The magnetically elicited PDI is slightly greater than the electrical, the difference being due to a larger Poes. ${ }^{53}$ This is thought to be due to activation of the accessory muscles because of spread of the magnetic field. ${ }^{553}$ In clinical practice the small difference in PDI with the magnetic technique is seldom important, except that it can give rise to a falsely short phrenic nerve conduction time. Magnetic stimulation, unlike electrical, is painless and it is usually possible to achieve reproducible stimulation without the problem of twitch potentiation. Magnetic stimulation has a higher and better defined lower limit of normal than electrical stimulation, and better correlation with sniff PDI which, in turn, increases its diagnostic sensitivity in patients with moderate diaphragm weakness ${ }^{54}$ and allows sequential studies in patients. ${ }^{55}$ Stimulation of the phrenic nerves anteriorly with a figure of eight coil allows easy and accurate quantification of hemidiaphragm function ${ }^{56}$ and, by using bilateral anterior stimulation, diaphragm function can be studied in supine subjects ${ }^{57}$ - for example, those undergoing coronary artery surgery ${ }^{58}$ and those in intensive care. For clinical studies it is likely that magnetic phrenic nerve stimulation will largely replace electrical stimulation, and phrenic nerve stimulation will be possible in circumstances not hitherto practical.

NON-INVASIVE ASSESSMENT OF DIAPHRAGM CONTRACTILITY Just as sniff oesophageal pressure is reflected in the nose, so twitch PoEs may be assessed at the mouth in both normal subjects ${ }^{59}$ and in patients with respiratory muscle weakness. ${ }^{60}$ In patients with COPD the equilibration of Poes with PMouth is slow and the technique is not, in practice, as useful. ${ }^{61}$ The combination of easy and painless magnetic stimulation of the phrenic nerves and the measurement of twitch mouth pressure (fig 3) opens the way for non-invasive assessment of diaphragm function. Interestingly, it has recently been reported that force generated during a diaphragmatic twitch may also be quantitatively assessed non-invasively by measuring the sound created by the contracting diaphragm. ${ }^{62}$

ASSESSMENT OF THE LOAD/CAPACITY BALANCE

Isolated diaphragm weakness - and even paralysis - is without life threatening sequelae, ${ }^{4}$ which underlines the fact that, for ventilatory failure to occur, load must exceed capacity. ${ }^{8}$ Although daytime ventilatory failure is not a feature of isolated bilateral diaphragm paralysis, ${ }^{4}$ such patients do have nocturnal desaturation, particularly during rapid eye movement (REM) sleep, and the importance of this has yet to be elucidated. ${ }^{463}$ In the clinical assessment of respiratory muscle dysfunction consideration of the ventilatory load is of great importance. The likelihood of additional load may be predicted if other investigations 


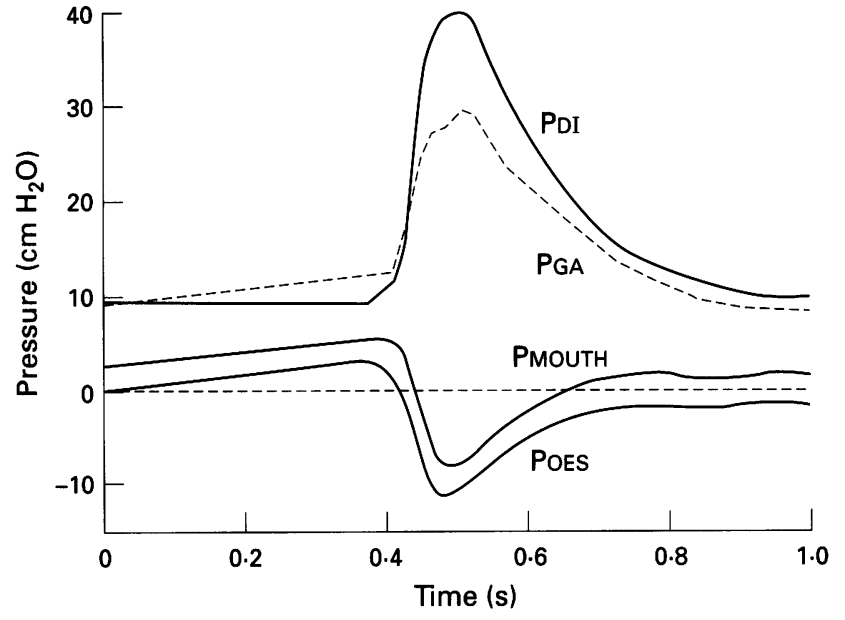

Figure 3 Pressures produced by cervical magnetic stimulation in a normal subject. PMOUTH closely follows oesophageal pressure (POES). $P D I=$ transdiaphragmatic pressure; $P G A=$ gastric pressure. Reproduced with permission from ref 60 .

indicate airways obstruction or restrictive lung or chest wall disease; the latter may be suggested by measurement of dynamic compliance and is easy to document with an oesophageal balloon in situ. Severe imbalance of the load/ capacity relationship is suggested by nocturnal hypoventilation with compensatory bicarbonate retention. Collapse of the upper airway during sleep may aggravate the situation and is relatively more common in patients with generalised neuromuscular disease.

\section{EXPIRATORY MUSCLE STRENGTH}

The only test of expiratory muscle strength generally available is the MEP which, although often useful, has the same limitations as the MIP manoeuvre. In our laboratory we commonly measure gastric pressure both during maximum coughs and maximum whistles (performed on a paediatric peak flow whistle). We believe that PGA obtained in this way is a useful supplement to MEP, although normal values have yet to be formally described. It is also possible to obtain a non-volitional measurement of expiratory muscle strength by administering a magnetic stimulation over the nerve roots at T10. Although this technique is not supramaximal it is, in physiologists at least, highly reproducible. $^{64}$

\section{LIMB MUSCLES}

When assessing patients with respiratory muscle weakness it is useful to assess the strength of peripheral skeletal muscles since weakness of these muscles is frequently evident in neuromuscular and systemic disease. ${ }^{2}$ Supramaximal electrical stimulation of the small muscles of the hand is possible $e^{65}$ but is painful and technically difficult. The maximum voluntary contraction force of the quadriceps is a reproducible measure of muscle strength provided the patient is conscious and fully motivated. ${ }^{66}$ Electrical stimulation using pads applied to the muscle is not supramaximal and, although useful in research studies of fatigue, is not a good clinical test of weakness. We have recently shown, however, that it is possible to obtain a painless reproducible supramaximal magnetic stimulation of the quadriceps by discharging a figure of eight coil over the femoral nerve in the femoral triangle. ${ }^{67}$ This offers the prospect of a complementary non-volitional test of quadriceps strength which may be conveniently undertaken in a respiratory muscle laboratory.

\section{Conclusion}

The range of techniques available to assess respiratory muscle weakness has greatly expanded in recent years. Sniff nasal pressure and magnetic twitch PDI are likely to be particularly important advances. How should the clinicians use these techniques? For screening patients with unexplained breathlessness and for diagnosing the presence of weakness a graded approach is best using tests in order of increasing complexity and invasiveness (fig 1); full respiratory muscle assessment will be required for only a few cases. For following patients with progressive neuromuscular problems - for example, motor neurone disease - where repeated measurements are required, simple procedures are most appropriate and the combination of VC and SNIP with MEP and quadriceps maximum voluntary contraction force would be one suitable combination. If a major treatment change - for example, non-invasive ventilation - is planned for such patients, more detailed muscle studies combined with sleep studies may be indicated. There is now no justification for relying on volitional tests alone in studies of fatigue, training and rehabilitation, and in patients unable or unwilling to make maximum voluntary efforts.

Reprint requests to: Professor J Moxham, Department of Thoracic Medicine, King's College School of Medicine and Dentistry, London SE5 9PJ, UK.

Respiratory Muscle Laboratories,

King's College and Royal Brompton Hospital,

M I POLKEY $M$ GREEN London, UK

J MOXHAM

1 Davison A, Mulvey D. Idiopathic diaphragmatic weakness. $B M F$ 1992:304: 492-4.

2 Mier-Jedrzejowicz A, Brophy C, Moxham J, Green M. Assessment of diaphragm weakness. Am Rev Respir Dis 1988;137:877-83.

3 Demedts M, Beckers J, Rochette F, Bulcke J. Pulmonary function in moderate neuromuscular disease without respiratory complaints. Eur $\mathfrak{F}$ Respir Dis 1982;63:62-7.

4 Laroche CM, Carroll N, Moxham J, Green M. Clinical significance of severe isolated diaphragm weakness. Am Rev Respir Dis 1988;138:862-6.

5 Hill NS. Noninvasive ventilation. Does it work, for whom, and how? Am Rev Respir Dis 1993;147:1050-5.

6 Murciano D, Rigaud D, Pingleton S, Armengaud M, Melchior J, Aubier M. Diaphragmatic function in severely malnourished patients with anorexia nervosa. Am $\mathcal{F}$ Respir Crit Care Med 1994;150:1569-74.

7 Decramer M, Lacquet L, Fagaud R, Rogiers P. Corticosteroids contribute to muscle weakness in chronic airflow obstruction. Am f Respir Crit Care Med 1994;150:11-16.

8 Moxham J. Respiratory muscle fatigue: mechanisms, evaluation and therapy. Br F Anaesth 1990;65:43-53.

9 Green M, Moxham J. Respiratory muscles in health and disease. In: Barnes P, ed. Respiratory medicine. Recent advances. Oxford: ButterworthHeinemann, 1993:252-75.

10 Smith PE, Calverley PM, Edwards RH. Hypoxemia during sleep in Duchenne muscular dystrophy. Am Rev Respir Dis 1988;137:884-8.

11 Gibson G. Diaphragmatic paresis: pathophysiology, clinical features and investigation. Thorax 1989;44:960-70.

12 Alexander C. Diaphragm movements and the diagnosis of diaphragmatic paralysis. Clin Radiol 1966;17:79-83.

13 Houston JG, Angus RM, Cowan MD, McMillan NC, Thomson NC. Ultrasound assessment of normal hemidiaphragmatic movement: relation to inspiratory volume. Thorax 1994;49:500-3.

14 Allen S, Hunt B, Green M. Fall in vital capacity with posture. $\mathrm{Br} \mathcal{F} \mathrm{Dis}$ Chest 1985;79:267-71.

15 Gibson G, Pride N, Newsom-Davis J, Loh L. Pulmonary mechanics in patients with respiratory muscle weakness. Am Rev Respir Dis 1977;115: patients

16 Chevrolet J, Delamont P. Repeated vital capacity measurements as predictive parameters for mechanical ventilation need and weaning success in Guillain Barré syndrome. Am Rev Respir Dis 1991;144:814-8.

17 Gaulthier C, Zinman R. Maximal static pressures in children. Respir Physiol 1983;51:45-61.

8 Leech J, Ghezzo H, Stevens D, Blecklake M. Respiratory pressures and function in young adults. Am Rev Respir Dis 1983;128:17-23.

19 Wilson SH, Cooke NT, Edwards RH, Spiro SG. Predicted normal values for maximal respiratory pressures in caucasian adults and children. Thorax 1984;39:535-8.

20 Black L, Hyatt R. Maximal respiratory pressures: normal values and relationships to age and sex. Am Rev Respir Dis 1969;99:698-702.

21 Bruschi C, Cerveri I, Zoia MC, Fanfulla F, Fiorentini M, Casali L, et al. Reference values of maximal respiratory mouth pressures: a population based study. Am Rev Respir Dis 1992;146:790-3.

22 Hamnegard C-H, Wragg S, Kyroussis D, Aquilina R, Moxham J, Green M. Portable measurement of maximum mouth pressures. Eur Respir $f$ M. Portable measu.

23 Aldrich T, Spiro P. Maximal inspiratory pressure: does reproducibility indicate full effort. Thorax 1995;50:40-3.

24 Gandevia SC, McKenzie DK. Activation of the human diaphragm during maximal static efforts. I Physiol Lond 1985;367:45-56.

25 Bellemare F, Bigland-Ritchie B. Central components of diaphragmatic fatigue assessed by phrenic nerve stimulation. $\mathcal{F}$ Appl Physiol 1987;62: $1307-16$. 
26 Allen GM, McKenzie DK, Gandevia SC, Bass S. Reduced voluntary drive to breathe in asthmatic subjects. Respir Physiol 1993;93:29-40.

27 Similowski T, Yan S, Gauthier AP, Macklem PT, Bellemare F. Contractile properties of the human diaphragm during chronic hyperinflation. $N$ Engl F Med 1991;325:917-23.

28 Koulouris N, Mulvey DA, Laroche CM, Green M, Moxham J. Comparison of two different mouthpieces for the measurement of PImax and PEmax of two different mouthpieces for the measurement of Pim
in normal and weak subjects. Eur Respir F 1988;1:863-7.

29 Miller JM, Moxham J, Green M. The maximal sniff in the assessment of diaphragm function in man. Clin Sci 1985;69:91-6.

30 Koulouris N, Mulvey DA, Laroche CM, Sawicka EH, Green M, Moxham $\mathrm{J}$. The measurement of inspiratory muscle strength by sniff esophageal, nasopharyngeal, and mouth pressures. Am Rev Respir Dis 1989;139:641-6.

31 Kyroussis D, Mills G, Hamnegard C-H, Wragg S, Road J, Green M, et al. Inspiratory muscle relaxation rate assessed from sniff nasal pressure. Thorax 1994;49:1127-33.

32 Heritier F, Rahm F, Pasche P, Fitting J-W. Sniff nasal pressure. A noninvasive assessment of inspiratory muscle strength. Am $\mathcal{f}$ Respir Crit Care Med 1994;150:1678-83.

33 Uldry C, Fitting J. Influence of airway obstruction on sniff nasal inspiratory pressure. Am $\mathcal{F}$ Respir Crit Care Med 1995;151:A414.

34 Murciano D, Aubier M, Bussi S, Derenne JP, Pariente R, Milic-Emili J. Comparison of esophageal, tracheal, and mouth occlusion pressure in patients with chronic obstructive pulmonary disease during acute respiratory failure. Am Rev Respir Dis 1982;126:837-41.

35 Hamnegard C-H, Wragg S, Kyroussis D, Mills GH, Polkey MI, Moxham J, Green M. Sniff nasal pressure measured with a portable meter. $A m \mathcal{F}$ Respir Crit Care Med 1995;151:A415.

36 Uldry C, Fitting J-W. Maximal values of sniff nasal inspiratory pressure in healthy subjects. Thorax 1995;50:371-5.

37 Pertuze J, Watson A, Pride N. Limitation of maximum inspiratory flow through the nose. Bull Eur Physiol Respir 1987;23(Suppl 12):344s.

38 Laroche CM, Mier AK, Moxham J, Green M. The value of sniff esophageal pressures in the assessment of global inspiratory muscle strength. Am Rev Respir Dis 1988;138:598-603.

39 Newsom-Davis J. Phrenic nerve conduction in man. $\mathcal{F}$ Neurol Neurosurg Psychiatry 1967;30:420-5.

40 Chen R, Collins S, Remtulla H, Parkes A, Bolton C. Phrenic nerve conduction study in normal subjects. Muscle Nerve 1995;18:330-5.

41 Close R. Dynamic properties of mammalian skeletal muscles. Physiol Rev 1972;52:129-97.

42 Bellemare F, Bigland-Ritchie B. Assessment of human diaphragm strength and activation using phrenic nerve stimulation. Respir Physiol 1984;58: 263-77

43 Wragg S, Hamnegard C, Road J, Kyroussis D, Moran J, Green M, et al. Potentiation of diaphragmatic twitch after voluntary contraction in norma subjects. Thorax 1994;49:1234-7.

44 Mador M, Magalang U, Kufel T. Twitch potentiation following voluntary diaphragmatic contraction. Am F Respir Crit Care Med 1994;149:739-43.

45 Mier A, Brophy C, Moxham J, Green M. Phrenic nerve stimulation in normal subjects and in patients with diaphragmatic weakness. Thorax normal subjects

46 Mier A, Brophy C, Moxham J, Green M. Repetitive stimulation of phrenic nerves in myasthenia gravis. Thorax 1992;47:640-4.

47 Laroche CM, Mier AK, Spiro SG, Newsom-Davis J, Moxham J, Green M Respiratory muscle weakness in the Lambert-Eaton myasthenic syndrome. Thorax 1989;44:913-8.
48 Mier A, Brophy C, Moxham J, Green M. Twitch pressures in the assessment of diaphragm weakness. Thorax 1989;44:990-6.

49 Laroche CM, Mier AK, Moxham J, Green M. Diaphragm strength in patients with recent hemidiaphragm paralysis. Thorax 1988;43:170-4.

50 Machetanz J, Bischoff C, Pilchlmeier R, Meyer B-U, Sader A, Conrad B. Magnetically induced muscle contraction caused by motor nerve stimulation and not by direct muscle activation. Muscle Nerve 1994;17:1170-5.

51 Barker A, Freeston I, Jalinous R, Jarrett J. Magnetic stimulation of the human brain and peripheral nervous system: an introduction and the results of an initial clinical evaluation. Neurosurgery 1987;20:100-9.

52 Similowski T, Fleury B, Launois S, Cathala HP, Bouche P, Derenne JP. Cervical magnetic stimulation: a new painless method for bilateral phrenic nerve stimulation in conscious humans. F Appl Physiol 1989;67:1311-8.

53 Wragg S, Aquilina R, Moran J, Ridding M, Hamnegard C-H, Fearn T, et al. Comparison of cervical magnetic stimulation and bilateral percutaneous electrical stimulation of the phrenic nerves in normal subjects. Eur Respir flectrical stimulation

54 Wragg S, Hamnegard C-H, Kyroussis D, Mills G, Green M, Moxham J. Assessment of diaphragm strength in patients using cervical magnetic stimulation. Am f Respir Crit Care Med 1994;149:A130.

55 Polkey MI, Kyroussis D, Keilty SEJ, Hamnegard CH, Mills GH, Green $\mathrm{M}$, et al. Exhaustive treadmill exercise does not reduce twitch transdiaphragmatic pressure in patients with COPD. Am $\mathcal{F}$ Respir Crit Care Med 1995 (in press).

56 Mills GH, Kyroussis D, Hamnegard CH, Wragg S, Moxham J, Green M. Unilateral magnetic phrenic nerve stimulation in unilateral diaphragm paresis. Thorax 1994;49:1058-9P.

57 Mills GH, Kyroussis D, Hamnegard CH, Polkey M, Green M, Moxham J. Bilateral magnetic stimulation of the phrenic nerves using an anterior approach. Thorax 1994;49:1058P.

58 Mills GH, Ponte J, Hamnegard C, Kyroussis D, Polkey M, Green M, et al. Human diaphragm contractility during intraoperative cooling. Am $\mathcal{f}$ Respir Crit Care Med 1995;151:A809.

59 Yan S, Gauthier AP, Similowski T, Macklem PT, Bellemare F. Evaluation of human diaphragm contractility using mouth pressure twitches. Am Rev Respir Dis 1992;145:1064-9.

60 Hamnegard C-H, Wragg S, Kyroussis D, Mills GH, Bake B, Green M, et al. Mouth pressure in response to magnetic stimulation of the phrenic nerves. Thorax 1995;50:620-4.

61 Similowski T, Gauthier AP, Yan S, Macklem PT, Bellemare F. Assessment of diaphragm function using mouth pressure twitches in chronic obstructive pulmonary disease patients. Am Rev Respir Dis 1993;147:850-6.

62 Petitjean M, Bellemare F. Phonomyogram of the diaphragm during unilateral and bilateral phrenic nerve stimulation and changes with fatigue. Muscle Nerve 1994;17:1201-9.

63 White J, Drinnan M, Smithson A, Griffiths C, Gibson G. Respiratory muscle activity and oxygenation during sleep in patients with muscle weakness. Eur Respir f 1995;8:807-14.

64 Kyroussis D, Mills G, Polkey M, Hamnegard CH, Moxham J, Green M. Magnetic stimulation of the abdominal muscles. Am $\mathcal{F}$ Respir Crit Care Med 1995;151:A415.

65 Merton P. Voluntary strength and fatigue. F Physiol 1954;123:553-64.

66 Edwards RH, Young A, Hosking GP, Jones DA. Human skeletal muscle function: description of tests and normal values. Clin Sci 1977;52:283-90.
function

67 Polkey M, Kyroussis D, Mills GH, Hamnegard CH, Howes TQ, Green $\mathrm{M}$, et al. Magnetic stimulation of the femoral nerve in man. Clin Sci 1995; 89:16P. 